Results: The original objective of WADEM was to improve the worldwide delivery of pre-hospital and emergency care during everyday and mass disaster emergencies. Whilst the Association has grown over the years, the founding objective has remained the same, "to work actively to solve technical, scientific, and political problems surrounding the management of emergency incidents".

The membership of WADEM is multi-disciplinary, international, collaborative, and diverse welcoming practitioners, researchers, educators, and administrators in this global healthcare endeavour.

Individual members are active in field operations, however, the organisation remains non-operational, fulfilling its mission through research, data collection, developing evidence-based standards, education, its international network, biennial World Congresses, peer-reviewed journal, committees, and task forces.

Conclusion: In collaboration with other international organisations, WADEM makes an important contribution to "Global Solutions for Global Crises".

Keywords: committees; congresses; disaster; education; emergency; humanitarian; global; networks; prehospital; research; standards; task forces; WADEM

Prebosp Disast Med 2002;17:s32-33.

\section{Problems of International Cooperation at the Interaction Level in the Network of WHO Collaborating Centres}

Gennady Victorovich Kipor; Sergey Fedorovich Goncharov All-Russian Centre for Disaster Medicine "Zaschita", Moscow, Russia

Objective: To characterize the actual situation in the priority activities of WHO/EHA's 14 Collaborating Centres, and to propose for discussion, the mechanisms for increasing their cooperation.

Methods: The programs and activities of the Collaborating Centres using the base of the logical Framework Approach were monitored and recorded. Global trends of the Centres Activity were analyzed.

Results: The joint activities of the Centres are coordinated in major part, only during the meetings convened once every three years. Each Centre is specialized in a definite area related to the regional peculiarity of emergencies, their geographical position, and periodicity (of natural calamities), as well as considering national peculiarities of their Disaster Medicine services.

For 2002-2003, the six most relevant topical fields for development of a coordination process in the network of Collaboration Centres were defined: 1) Public health policy in emergency and juridical support of humanitarian operations at the international level activities under the motto, "Health is a focal point for all humanitarian operations"; 2) Management and informational exchange in the sphere of humanitarian interaction in Disaster Medicine as a basis for WHO management functions; 3) Political and technical aspects of WHO humanitarian operations at the territorial and local or tactical and operation levels (according to WHO classification); 4) International partnership and resources, mobilized to solve priority public health humanitarian operations; 5) Strengthening of the WHO's role through development of the system of personnel management; and 6) Preparation of more perfect program, field practice and expertise.

Conclusion: The main first priority fields of Collaborating Centres activities have to comprise the Info- Supply Management systems and experience changing in the branches of investigation and field practice supported by national institutions and led by a Standing Committee containing the representatives of Collaborating Centres.

Keywords: Disaster Medicine; management; priorities; WHO Collaborating Centres

Prehosp Disast Med 2002;17:s33.

\section{"Action Plans"-Declaration of the 5th APCDM (30 September 2000)}

Wayne Greene, $P h D ;{ }^{1}$ Diana Ericson; ${ }^{2}$

Kendall Ho, MD FRCPC 3

1. Director, Disaster Preparedness Resource Centre, University of British Columbia

2. Manager, Disaster Preparedness Resource Centre, University of British Columbia

3. Associate Dean and Director, Division of Continuing Medical Education, Faculty of Medicine, University of British Columbia

The 5th APCDM was held in Vancouver, British Columbia, Canada, 27-30 September 2000. It brought together more than 300 delegates from 35 countries. The goal of the 5th APCDM was to provide a forum within which the international community, health professional and disaster experts, as well as government and non-government agencies, could explore disaster management techniques and discuss emergency medical methods, models and technologies. Eight themes were developed emphasizing the interdisciplinary roles played by the delegates. Two Co-chairs, who had broad experience and expertise, oversaw each theme and lead the discussions in addition to collecting and summarizing the ideas presented. The eight themes were:

1. Disaster Coordination and Management

Disaster is a collective responsibility, requiring a coordinated response from all parts of society, bring together diverse groups of specialists and volunteers and requires extraordinary coordination and management of people, resources, facilities and approaches.

2. Telebealth and Communication Technologies in Health

Rapid innovations and improvements in communication technologies have opened many new channels for health education and delivery, as well as disaster management. Theme 2 examined the role and applicability of these technologies to disaster medicine and management and the various issues involved in their use.

3. Sharing Pacific Rim Experiences in Disasters

Theme 3 provided an opportunity to address any unique hazards facing the Pacific Rim.

4. Effective Models for Medical and Health Response Coordination 
Disaster medicine has become an increasingly important field. Evolving from a fairly narrow concept of basic medical service delivery at the disaster site, it now encompasses a broad humanitarian response with long-term implications for development. To effectively respond to this relatively new, complex mandate, it is essential to find effective models of coordination to ensure that medical and health services can meet the standards now expected in a disaster situation. This theme explored various models, noting both the strengths that can be built on and the weaknesses that still need to be overcome.

\section{Application of International Standards to Disasters}

The need for the application of international standards has been evolving over the last decade. With hundreds of nongovernmental agencies now working in humanitarian assistance, there is a growing need to coordinate and systematize their efforts to ensure a consistent level of response. The crisis of Rwanda, and the complete international failure to provide adequate protection, has highlighted the need for accountability in humanitarian assistance.

6. Multidisciplinary Team Interaction: Issues and Possible Solutions

Multidisciplinary team interaction has become a commonplace phrase in the discussion of disaster response. Nevertheless, repetition of the words does not seem to elucidate or alleviate this complex dynamic process. Theme 6 explored multidisciplinary team interactions and attempted to identify some of the key issues and possible solutions.

7. Sharing International Experiences in Disasters

Theme 7 provided an opportunity to share specific experiences of disasters that happened outside the Asia-Pacific Rim area. A wide range of lessons, some of which appeared in other track discussions, but many of which were unique to this forum, emerged.

\section{Education Issues in Disaster Medicine}

Because of the increasing impact that disasters have on the social, environmental and economic structures of society, greater international attention has been focused on how to prevent, mitigate, respond and recover from such cataclysmic events. Theme 8 explored issues that need attention in disaster medicine education. Discussion ranged from specific topics and classroom techniques to research areas and methodology. The one unanimous conclusion was that we need more and better education on the disaster phenomenon, both in its impacts and in our response to them.

The conference was devoted to the task of establishing priorities and creating an agenda for action. Key actions from the discussions during the above theme sessions are listed below:

\section{Communications}

- Identify existing regional telehealth groups and gather lessons to be learned from them

- Form a telehealth advisory group to work with regional groups to compile telehealth initiatives, identify international protocols in telehealth already in existence, and identify "Requests for Comments" before setting international standards. This could be an initiative of APCDM, WADEM, or the European Society of Emergency Medicine

- Increase volunteer and corporate partnerships in the fields of telehealth and telecommunications and invite them to future APCDM meetings.

\section{Education}

- Formalize education in disaster medicine and management. The World Health Organization and WADEM should take a leadership role.

- WADEM is requested to hold a conference with a focus on qualitative research.

- WHO is requested to continue the provision of international research teams, and to be an advocate for the development of national disaster research infrastructure.

- Make research findings and reports available on web sites of such organizations as WHO and PAHO.

- Develop the translation of research for community utilization. WHO and PAHO are organizations that are requested to consider this action.

- WADEM/APCDM are requested to focus future conferences on applied research.

\section{Information and Data}

- Create an Information and Data Clearinghouse on Disaster Management to collect, collate and disseminate information

- Collect data using standardized tools, such as CAR (Capability Assessment for Readiness, US-FEMA and National Emergency Management Association) or Hazmat indices.

- Analyze incentives and disincentives for disaster readiness and establish mechanisms for addressing the obstacles to preparedness.

- WADEM is requested to develop a web site providing a resource list of interdisciplinary institutions and response activities, organized by country, topic and research interests. Links to other pertinent web sites should be provided.

\section{Interdisciplinary Development}

- Focus on the inter-disciplinary nature of disaster response through more conferences encompassing grassroots efforts and through WADEM publications.

- Develop and apply a standardized template of Needs Assessment for multidisciplinary teams. Team Needs Assessment is essential to determine the following:

1. Local response and international assistance required

2. Appropriate command system

3. Psychosocial impact and support necessary

\section{Psychosocial Aspects}

- Incorporate relief for caregivers into action plans. This should include prime family members who are also caregivers.

- Implement measures that give survivors control over the recovery process.

\section{Response Management}

- Define relationships and roles between governments, military and security personnel, NGOs and civic groups. Use an international legal framework and liability to reinforce accountability of disaster responders.

- Establish a more sophisticated use of the media during disasters.

- Establish standards in key areas. The World Association for Disaster and Emergency Medicine (WADEM) is requested to write "White Papers" on standards for the 
following areas: management, health/public health, education/training, psychosocial, disaster plans.

- Establish taskforces to anticipate and resolve issues around evolving and emerging disasters (e.g. chemical biological terrorism, landmines, emerging infectious diseases). WADEM was again identified as the vehicle for promoting this action.

All abstract submissions for the 5th APCDM were published in Prehospital and Disaster Medicine, Vol. 15, No. 3, 2000. The "Proceeding for the 5th Asia-Pacific Conference on Disaster Medicine: Creating an Agenda for Action" were published in Prehospital and Disaster Medicine, 2001;16(1):18-21.

Keywords: action; Asia-Pacific; recommendations; tasks

Prebosp Disast Med 2002;17:s33-35.

\section{Disaster Management and Coordination of the International Red Cross Movement Yasuo Tanaka}

Assistant Director, Planning Division, International Relations Department, Japanese Red Cross Society, Japan

The International Red Cross Movement coordinates and directs international assistance to victims of armed conflicts and natural disasters, to refugees and internally displaced persons, and in health emergencies. I will first introduce characteristics of the disaster management and the coordinating system of the International Red Cross, i.e., International Federation of Red Cross and Red Crescent Societies and International Committee of the Red Cross.

Another focus will be on roles and responsibilities of non-medical relief managers who should act as effective partners for medical relief personnel in planning, budgeting, implementing, coordinating, monitoring, and evaluating humanitarian operations. It is critically important that both medical and non-medical relief players have good understanding on mutual strengths and responsibilities in common pursuit of achieving effective disaster response management.

Keywords: disasters; management; managers; Red Cross; relief; responsibilities; roles

Prebosp Disast Med 2002;17:s35. 